\title{
Multi objective reactive power and voltage optimization of distribution network based on adaptive genetic annealing algorithm
}

\author{
YANG Yong ${ }^{1}$, CHEN Lei ${ }^{1}$, ZHENG Weiyan ${ }^{2}$, WEI Xinquan ${ }^{3 *}$, LV Guangxian ${ }^{3}$, LIU Peng ${ }^{3}$ \\ ${ }^{1}$ State Grid Zhejiang Electric Power Co., Ltd., Hangzhou, Zhejiang Province, 310007, China \\ ${ }^{2}$ State Grid Zhejiang Electric Power Co., Ltd. Hangzhou Power Supply Company, Hangzhou, Zhejiang Province, 310016, China \\ ${ }^{3}$ State Grid Shanghai Energy Interconnection Research Institute Co., Ltd., Shanghai, 201210, China
}

\begin{abstract}
In this paper, a multi-objective reactive power optimization model of distribution network is established, which takes the minimum of line loss, reactive compensation capacitor switching loss and node voltage deviation as objective, considering the constraints of node voltage, reactive power of wind turbine, capacitor switching times. The improved adaptive genetic annealing algorithm is used to solve the model. IEEE33 system is taken as an example to verify the effectiveness of the reactive power optimization model. When the shunt capacitor and wind turbine are in the optimal reactive power compensation, the line loss of the distribution network can be minimized.
\end{abstract}

\section{Introduction}

Reactive power optimization of distribution network is usually a multi-objective optimization problem which considers the economy and security of distribution network operation ${ }^{[1]}$.

At present, many scholars use intelligent optimization algorithm to solve the reactive power optimization problem. Wang ${ }^{[2]}$ proposed a chaos particle swarm optimization algorithm based on golden section to solve the reactive power optimization. Zhao ${ }^{[3]}$ designed an adaptive phased genetic algorithm to solve the reactive power planning problem. Yan ${ }^{[4]}$ designed a two-level optimal reactive power compensation model and solved the model by harmonic search particle swarm optimization algorithm. Liu ${ }^{[5]}$ established a multiobjective optimization model and solved it with NSGAII algorithm. $\mathrm{Hu}^{[6]}$ added the penalty function of investment scale constraint in the objective function and used genetic algorithm to solve the optimal configuration of reactive power compensation. $\mathrm{Hu}^{[7]}$ used the genetic algorithm and the two-level dynamic programming to solve the optimal operation scheme of the whole day equipment.

The doubly fed induction generator (DFIG) does not absorb the grid reactive power when it is running ${ }^{[8]}$. Many scholars established the distribution network reactive power optimization model considering DFIG reactive power compensation ${ }^{[9]}$.

This paper considers the randomness of the active output and load of DFIG. Monte Carlo method is used to sample all day wind speed, and k-means algorithm is used to get wind speed scene division. The reactive power optimization model is established to minimize the line loss, capacitor switching cost and node voltage deviation in the whole day, and the improved adaptive genetic annealing algorithm is used to solve the model.

\section{Reactive power optimization model of distribution network}

\subsection{Objective function}

At time $k$, the power loss in line $l_{i j}$ is as follows.

$$
p_{i j, k}=\sum_{i=1}^{N} \frac{P_{i, k}^{2}+Q_{i, k}^{2}}{U_{i, k}^{2}} R_{i j}
$$

$N$ is the number of distribution system nodes. $P_{i, k}$ and $Q_{i, k}$ is the active and reactive power of the node. $U_{j, k}$ is node voltage and $R_{i j}$ is the branch impedance. The goal of objective function $F_{1}$ is to minimize the total line power loss throughout the day.

$$
\min F_{1}=\sum_{k=1}^{24} \lambda_{k} \cdot p_{i j, k}
$$

Here $\lambda_{k}$ is the unit power loss cost of the $k$-th period. The goal of objective function $F_{2}$ is to minimize the equipment loss caused by capacitor switching.

$$
\min F_{2}=\sum_{k=1}^{C} \phi\left(\mu_{k}\right)
$$

$\mu_{k}$ is the total switching times of the $k$-th capacitor in the whole day, and $\phi\left(\mu_{k}\right)$ is the cost loss caused by 
capacitor switching. $C$ is the total number of shunt capacitor banks.

Objective function $F_{3}$ is to minimize the node voltage deviation of the distribution network, where $U_{i}$ and $U_{N}$ is the actual voltage and rated voltage of the node.

$$
\min F_{3}=\frac{1}{N} \sum_{i=1}^{N}\left|U_{i}-U_{N}\right|
$$

\subsection{Constraint condition}

The power balance equation of the node is as follows.

$$
\left\{\begin{array}{l}
\Delta P_{i}=\sum_{w=1}^{w_{i}} P_{i, w}-U_{i} \sum_{j \in n(i)} U_{j}\left(G_{i j} \cos \theta_{i j}+B_{i j} \sin \theta_{i j}\right)=0 \\
\Delta Q_{i}=\sum_{w=1}^{w_{i}} Q_{i, w}-U_{i} \sum_{j \in n(i)} U_{j}\left(G_{i j} \sin \theta_{i j}-B_{i j} \cos \theta_{i j}\right)=0
\end{array}\right.
$$

$P_{i, w}$ and $Q_{i, w}$ is the active and reactive output of single wind turbine at node $i . w_{i}$ is the number of DFIG incorporated by node $i$. The reactive power constraints for wind turbine is as follows.

$$
Q_{\min } \leq Q \leq Q_{\max }
$$

The node voltage constraint is as follows.

$$
U_{\text {min }} \leq U_{i} \leq U_{\text {max }}, i=1,2, \ldots, N
$$

The switching times of shunt capacitor is limited as follows.

$$
0 \leq S_{i} \leq S_{\max }
$$

Where $S_{\max }$ is the maximum allowed number of capacitor switching times.

\subsection{Adaptive genetic annealing algorithm}

The following adaptive crossover probability $p_{c}$ and probability of variation $p_{m}$ is used ${ }^{[10]}$.

$$
\begin{gathered}
p_{c}=\left\{\begin{array}{c}
k_{1} \frac{f_{\text {max }}-f^{\prime}}{f_{\text {max }}-f_{\text {avg }}}, f^{\prime} \geq f_{\text {avg }} \\
k_{3}, f^{\prime}<f_{\text {avg }}
\end{array}\right. \\
p_{m}=\left\{\begin{array}{c}
k_{2} \frac{f_{\text {max }}-f}{f_{\text {max }}-f_{\text {avg }}}, f \geq f_{\text {avg }} \\
k_{4}, f<f_{\text {avg }}
\end{array}\right.
\end{gathered}
$$

$f_{\text {avg }}$ is the average fitness of population. $f_{\max }$ and $f_{\min }$ is the maximum and minimum fitness of the population. $f^{\prime}$ is the maximum fitness of two chromosomes to be crossed.

\section{Case study}

IEEE33 node system considering wind turbine access and shunt capacitor is shown in Figure 1. Node 17 and 32 is respectively connected to $300 \mathrm{MW}$ and $200 \mathrm{MW}$ DFIG. Parallel compensation capacitors are connected at node 12 and 28 , with capacity of $3 \times 300$ kvar and $2 \times 300$ kvar respectively.

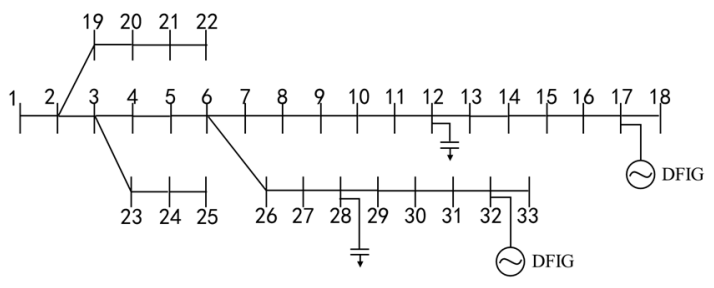

Figure 1 System diagram of IEEE33 connected to DFIG and capacitor

Figure 2 shows the curve of active power loss and node voltage before and after reactive power optimization. When DFIG and capacitor participate in reactive power regulation at the same time, it can effectively reduce the system power loss and improve the nodes voltage, as shown in Figure 3.

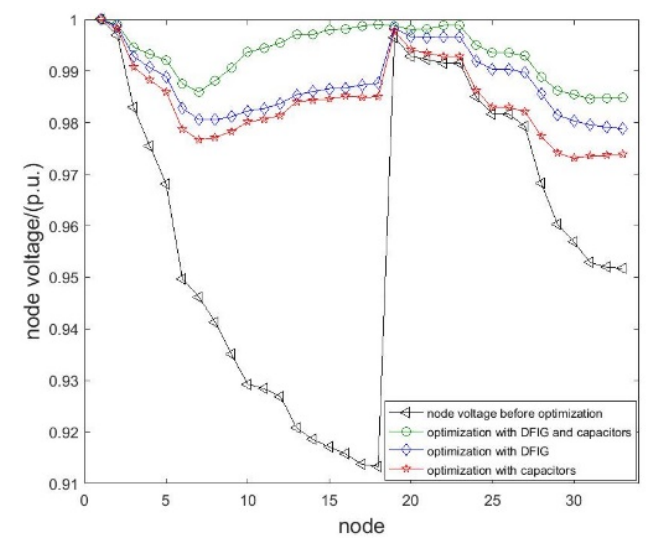

Figure 2 Node voltage curve before and after optimization

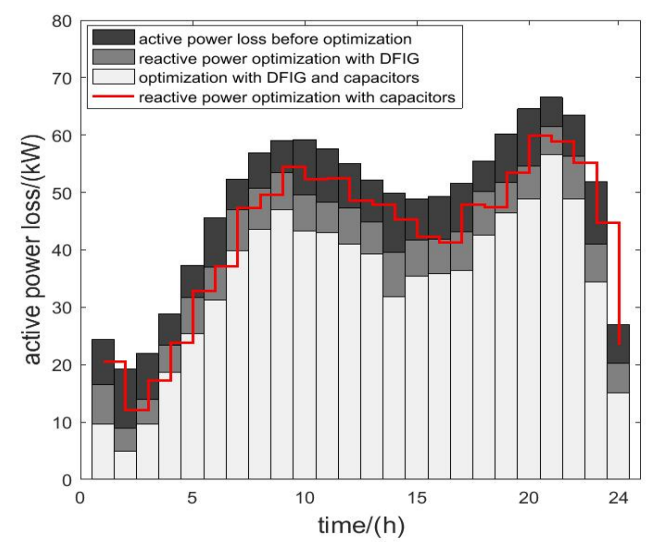

Figure 3 Active network loss before and after optimization 


\section{Conclusion}

In this paper, a multi-objective reactive power optimization model with minimum of line loss, capacitor switching cost and node voltage deviation is established. The improved adaptive genetic annealing algorithm is used to solve the model. A simulation of IEEE33 system node verified the validity of the model.

\section{Acknowledgement}

This paper was supported by the science and technology project of the headquarters of State Grid Corporation of China (project code: 5400-201919144A-0-0-00).

\section{References}

1. $\mathrm{Xu} \mathrm{ZL}$, Huang C. Reactive Power Optimization for Distribution Network Containing Wind Power Unit in Electricity Market Environment[J]. Proceedings of the CSU-EPSA, 2020,32(1):131-137.

2. Wang C, Wang X, Yao G. Application of golden section based chaos particle swarm optimization algorithm in distribution network reactive power optimization $[\mathrm{J}]$. Power System Protection and Control, 2012, 40(7):31-36.

3. ZHAO Junguang, WANG Zhuding, ZHANG Zongyi. A Dynamic Upper Limit to Node Compensation Based Hybrid Optimization Algorithm for Reactive Power Planning in Distribution Networks[J]. Automation of Electric Power Systems, 2009, 33(23):69-74.

4. Yan Y, Wu W, Zhang Y. Bi-level optimal allocation of reactive power compensation considering active management measure[J]. Power System Protection and Control, 2017, 45(12):60-66.

5. Liu XP, Liu TQ, Li XY. Optimal reactive power planning in distribution system with wind power generators[J]. Power System Protection and Control, 2010, 38(20):130-135.

6. Hai-Yan HU, Xiao-Meng W U, Jian L. Genetic algorithm based optimal dynamic planning of lowvoltage side reactive power compensators[J]. Electric Power Automation Equipment, 2005, 25(3):25-29.

7. Hu XY, Wang WP, Wang ZD. A practical twophase optimization method of dynamic var optimization in a distribution system[J]. Power System Protection and Control, 2015,(3):14-21.

8. Rong F, Li PY, Zhou SJ. Coordinated Optimal Control with Loss Minimization for Active and Reactive Power of Doubly Fed Induction GeneratorBased Wind Farm $[\mathrm{J}]$. Transactions of China Electrotechnical Society, 2020,35(3):520-529.

9. Ruan HB, Gao HJ, Liu JY. A Distributionally Robust Reactive Power Optimization Model for Active Distribution Network Considering Reactive Power Support of DG and Switch Reconfiguration[J]. Proceedings of The Chinese Society for Electrical Engineering, 2019,39(3):685695.

10. Srinivas M, Patnaik LM. Adaptive probabilities of crossover and mutation in genetic algorithms[J]. IEEE Transactions on Systems Man \& Cybernetics, 1994, 24(4):656-667. 